\title{
Tumor de células gigantes en un paciente pediátrico
}

\section{Reporte de un caso y revisión de la literatura}

\author{
Reynoso-Soto Leonel*, Cervantes-Gudiño Jorge Enrique ${ }^{* *}$
}

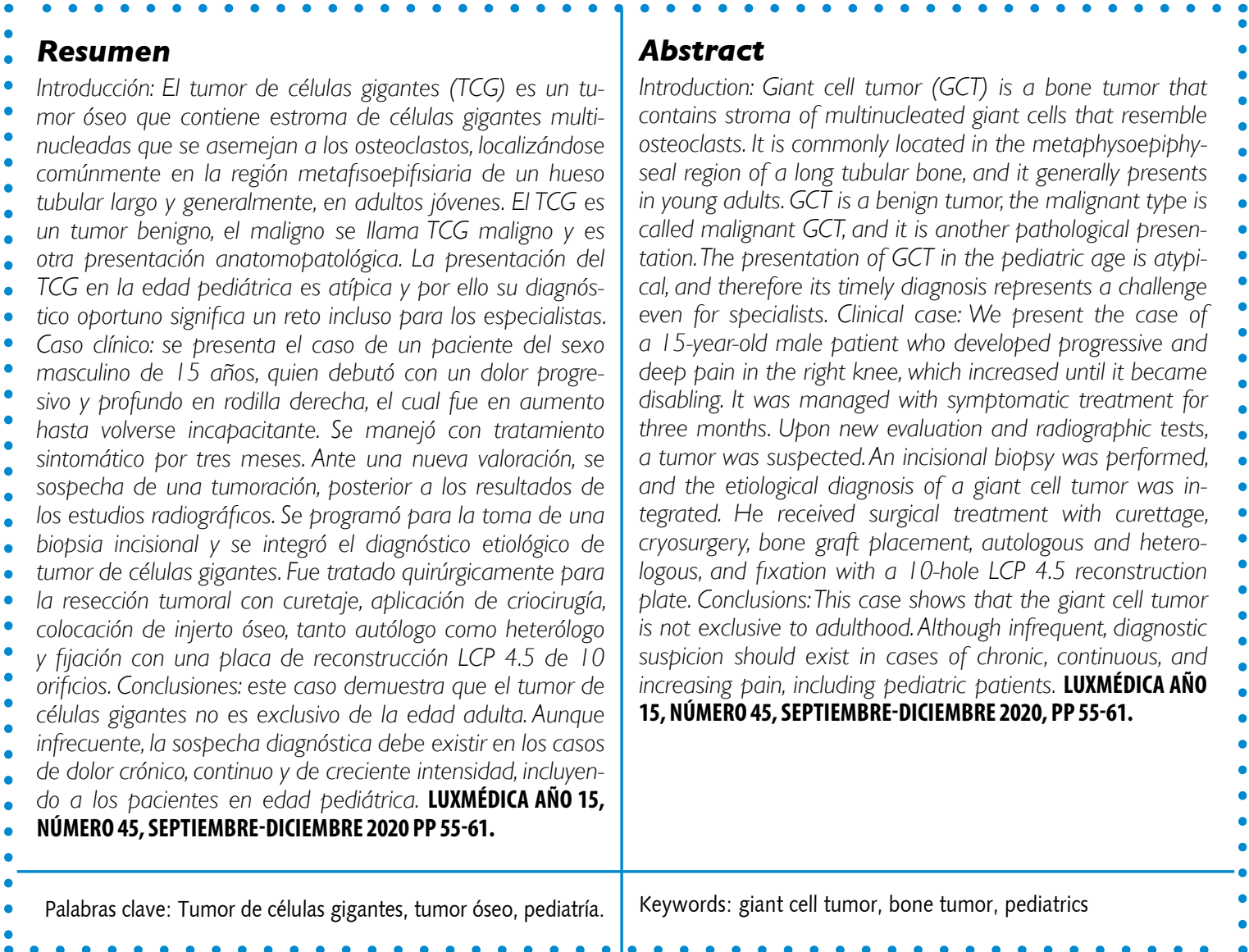

* Médico residente de 3er año de la especialidad de Ortopedia y Traumatología del Centenario Hospital Miguel Hidalgo, Aguascalientes, Ags. México. https://orcid.org/0000-0002-5289-7265 Correo electrónico leonelreynoso15@hotmail.com

** Médico Adscrito al Servicio de Ortopedia y Traumatología, Departamento de Ortopedia Pediátrica, Centenario Hospital Miguel Hidalgo. Aguascalientes, Ags. México. https://orcid.org/0000-0003-1803-1924 Correo electrónico ortopedcervantesgudi@hotmail.com

Fecha de recibido: 30 de junio de 2020

Fecha de aceptación: 20 de agosto 2020

Correspondencia: Dr. Jorge Enrique Cervantes Gudiño. Departamento de Ortopedia Pediátrica, Servicio de Ortopedia y Traumatología. Centenario Hospital Miguel Hidalgo. Avenida Gómez Morín S/N. La Estación, Alameda. Código postal 20259. Aguascalientes, Ags. México. Teléfono 4499946720. Correo electrónico ortopedcervantesgudi@hotmail.com 


\section{Introducción}

El tumor óseo de células gigantes benigno (GCTB), es un tumor óseo primario bien conocido con lesiones osteolíticas típicamente benignas y localmente agresivas. Representa del 3\% al $8 \%$ de todos los tumores óseos primarios en países occidentales, con una mayor incidencia en mujeres entre las edades de 20 y 50 años. Es poco frecuente encontrarlo en pacientes con fisis abiertas. ${ }^{1,2}$ Corresponde al $5 \%$ de todas las neoplasias primarias del hueso. Es ligeramente más común en mujeres entre 20 y 45 años, ${ }^{1-3}$ tiene una incidencia de aproximadamente 1 caso por cada millón de habitantes al año. ${ }^{3}$ En general, el GCTB puede ocurrir en cualquier parte del esqueleto, aunque, aproximadamente del 50\% al $65 \%$ de los GCTB se encuentran en el área de la rodilla, predominantemente en la zona metafisoepifisiaria del fémur distal y tibia proximal. Después de la rodilla, el radio distal y el húmero superior son ubicaciones frecuentes, también ocurre en apófisis como el trocánter mayor del fémur, en las raras ocasiones en que se ve GCTB en un esqueleto con fisis abierta, se ve en la metáfisis o la epífisis del hueso, alrededor del 15\% de los casos afectan los huesos planos, la pelvis, el sacro o vértebras. ${ }^{1-5}$

Sin tratamiento inmediato, el tumor puede producir destrucción ósea, inestabilidad de la articulación de la rodilla e invasión de los tejidos blandos circundantes normales, lo que eventualmente conduce a la pérdida de función e incluso amputación. ${ }^{1,6}$

Los GCTB crecen de manera expansiva y penetran fácilmente la corteza del hueso o incluso causan fracturas patológicas. Aunque rara vez se expanden hacia la cavidad articular, invaden el hueso subcondral, que afecta gravemente la función de la articulación de la rodilla. ${ }^{4,7}$ Para su diagnóstico la radiografía convencional generalmente muestra una lesión metafiso-epifisiaria, lítica excéntrica de patrón geográfico, sin esclerosis periférica, que se extiende al hueso subcondral, en un paciente con fisis cerradas. $2,4,8-10$

Todavía existe controversia sobre el tratamiento quirúrgico de GCTB en la articulación de la rodilla, ya que uno de los retos en el tratamiento de pacientes de estas edades con tumores cercanos a la fisis es la repercusión sobre el crecimiento y posibles deformidades angulares. ${ }^{11}$ Para lograr un equilibrio entre la eliminación completa de tumores para reducir la recurrencia y preservación de la función de la articulación de la rodilla tanto como sea posible se vuelve la pieza clave para que los médicos equilibren el tratamiento. ${ }^{12}$

\section{Presentación de caso clínico}

Paciente masculino de 15 años que inicia su padecimiento actual en febrero del 2019 con dolor en rodilla derecha, que se caracteriza por ser progresivo e incapacitante. Refiere que en el periodo entre el primer mes y segundo mes de evolución acudió con un médico general de forma particular, quien le prescribió analgésicos; 
el paciente no presentó mejoría y al agregarse incapacidad para la marcha, en mayo acudió al servicio de urgencias en el hospital de Pabellón de Arteaga, donde, con radiografía previamente tomada de forma externa, es atendido por el Servicio de Traumatología, el cual solicita resonancia magnética al identificar lesión ósea en metáfisis proximal de la tibia.

El paciente presentó un cuadro agudo de dolor por lo que acudió al Servicio de Urgencias del Centenario Hospital Miguel Hidalgo y fue ingresado para analgesia y protocolo diagnóstico. Se solicitó interconsulta al Servicio de Traumatología y Ortopedia con el objetivo de realizar biopsia ósea.

Se realizó una radiografía anteroposterior y una lateral de rodilla derecha, donde se observó una lesión ósea en tibia, en la región metafisoepifisiaria proximal, sin afectación de la epífisis, con reacción perióstica y destrucción ósea de cortical anterior, posterior y medial. Se observó edema de tejidos blandos en toda su circunferencia, además de una lesión de $5 \mathrm{~cm} \times 5 \mathrm{~cm}$ en sus diámetros más amplios, con imagen heterogénea radiolúcida en su mayor área. Las corticales de la tibia se encontraron disminuidas en grosor y se observó en la cortical anterior el triángulo de Codman, la ausencia de cortical posterior en un área de $3.9 \mathrm{~mm}$ y la ausencia de cortical lateral en un área de $2 \mathrm{~mm}$. Se observó también una reacción perióstica con imagen en cortical lateral de hojas de cebolla. Existía una imagen de discontinuidad ósea en cortical medial que sugería una fractura en terreno previamente lesionado (figura 1).

Los resultados de la resonancia magnética nuclear ( $R M N)$ mostraron una lesión a nivel metafisiaria proximal de tibia derecha en sus secuencias coronal y axial T2 con una lesión hiperintensa y en la secuencia axial T1 una lesión hipointensa, donde no se observan trabeculaciones, con destrucción de las corticales anterior, posterior y medial. Dicha lesión invadía la fisis en aproximadamente $12 \mathrm{~mm}$ en la parte más central del hueso. No se observó invasión a compartimientos de la pierna ni al paquete neurovascular posterior. El peroné no se encontraba afectado.

Se realizó una biopsia en tibia proximal derecha y se envió al Servicio de Patología, que confirmó el diagnóstico de tumor de células gigantes. El paciente fue sometido a tratamiento quirúrgico a base de legrado de tumor, con crioterapia y colocación de injerto autólogo de peroné, además de 60 gramos de chip óseo, reducción abierta y fijación interna con placa LCP 4.5 en T de 10 orificios. Actualmente el paciente se encuentra con una evolución favorable, sin dolor, ya comenzando con la descarga de peso.

\section{Discusión}

El GCTB es un tumor óseo benigno agresivo que generalmente ocurre durante la tercera y cuarta décadas de la vida, habitualmente en pacientes con fisis cerradas, con una preponderancia femenina, con frecuencia elevada de recurrencia y potencial morbilidad por destrucción ósea y afectación articular debido a su ubicación. 7,13,14
En esta ocasión hemos presentado el caso inusual de un paciente adolescente de 15 años quien aún presenta fisis abiertas, con un GCTB en tibia proximal derecha. Si bien, el diagnóstico de sospecha se realizó por las características clínicas, como el dolor intenso, variabilidad, inicio y modos de alivio de éste, fue más importante considerar la velocidad de crecimiento de la masa 
en la pierna. Por supuesto que los estudios de imagen son indispensables y la biopsia que permite el diagnóstico histopatológico, y da a conocer la naturaleza tumoral con precisión. ${ }^{13-17}$

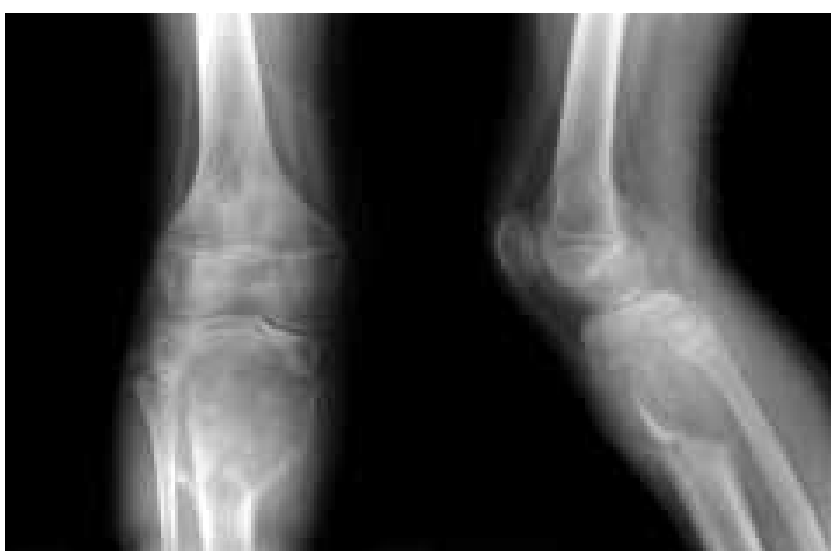

Figura 1. Imágenes radiográficas prequirúrgicas donde se observa la lesión descrita en el texto.

En el caso aquí presentado, el dolor fue el primer síntoma, pero ante la falta de sospecha clínica inicial, éste fue subestimado y considerado propio del crecimiento, hasta que su severidad pasó, de manifestarse únicamente durante actividad física, a presentarse inclusive en reposo e imposibilitar la movilidad. La pérdida ósea por la actividad osteoclástica resulta en un aumento de la producción de prostaglandinas y eso genera el dolor. Por otro lado, el dolor en reposo o nocturno es causado por el constante aumento del volumen tumoral que genera expansión del periostio. 8,9

A través de la clasificación de Campanacci, es posible clasificar al tumor de células gigantes por su actividad biológica y su afección intracompartimental, lo cual es útil para orientar el manejo terapéutico más apropiado. ${ }^{8}$ De acuerdo con los datos del paciente aquí presentado, se encontraba en un grado 3 en la escala Campanacci. Según la evidencia existente, el manejo para un grado 3 es el curetaje de la tumoración y el uso de una terapia local coadyuvante, como la implementación de algún agente químico o físico ya sea nitrógeno líquido, quimioterapia, radioterapia o aplicación de cemento de polimetilmetacrilato (PMMA). Este último ha mostrado la disminución de la reincidencia a valores entre el $6 \%$ y $25 \%$. $^{7,10} \mathrm{Sin}$ embargo, el empleo de cemento de PMMA posee efectos citotóxicos que permiten generar hipertermia local en la zona del injerto, induciendo necrosis de las células tumorales residuales, por lo cual ofrece el beneficio de la mejor reducción de recidivas. ${ }^{12}$

Existen muy pocas series y reportes de caso que presentan TCG en niños y adolescentes debido a su baja frecuencia en este grupo etario, lo que hace que su tratamiento en esta población esté basado principalmente en la experiencia en pacientes adultos. ${ }^{11}$

Los GCTB en la articulación de la rodilla son un desafío clínico en ortopedia, ya que la rodilla es la articulación que recibe mayor carga de peso con altos requisitos funcionales. Además, biológicamente, GCTB muestra un crecimiento expansivo, que puede fácilmente romper la corteza ósea e incluso causar fracturas patológicas. ${ }^{12}$ 
Se ha reportado que el tratamiento con peróxido de hidrógeno reduce la tasa de recurrencia y aumenta la supervivencia acu- mulada libre de recurrencia. In vitro se ha observado la inducción de apoptosis. ${ }^{13,14}$

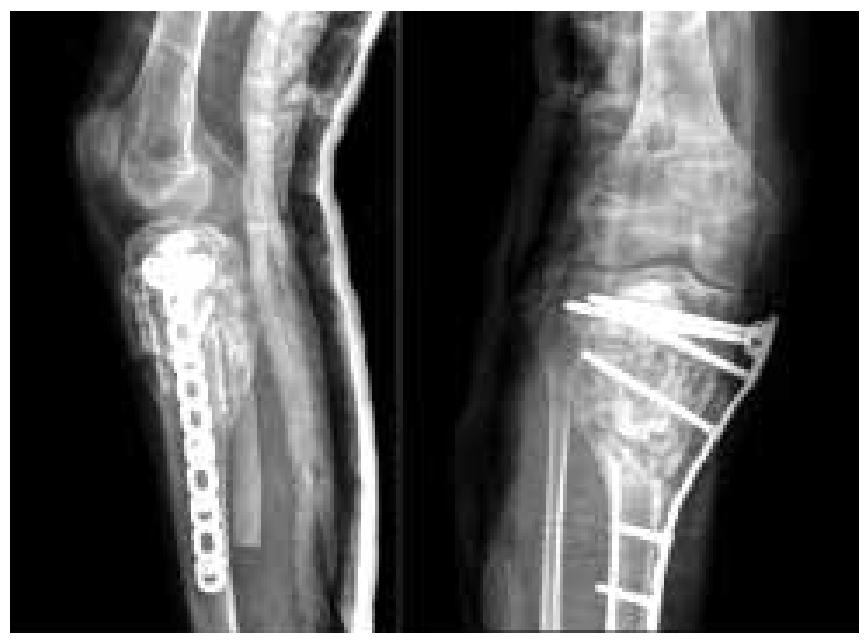

Figura 2. Radiografías postquirúrgicas

Por supuesto, después del legrado, el defecto óseo generalmente debe ser reconstruido con algún material. La pregunta más importante es cómo llenar la cavidad después del legrado extenso del GCTB intralesional. A pesar de los diversos rellenos biológicos y no biológicos, no hay consenso para la reconstrucción de defectos óseos después del legrado con GCTB alrededor de la rodilla. En teoría, el injerto, aloinjerto, material uso de sostén óseo o andamiaje no biológico (cemento) ideal debería proporcionar soporte mecánico y tener la capacidad de ser reabsorbido y reemplazado por el hueso huésped a largo plazo sin dañar la integridad mecánica del hueso. ${ }^{13,14,16}$ En nuestro caso decidimos colocar injerto autólogo tomado de peroné, en combinación con chip óseo para rellenar en su totalidad el defecto provocado por el tumor y el legrado agresivo. Además, una vez que se consigue rellenar el defecto óseo, es recomendable utilizar material de osteosíntesis para dar un mayor soporte a la reparación, así como una mejor estabili- dad a la zona afectada para evitar un colapso posterior de dicha zona. Motivo por lo que, en el caso de nuestro paciente, se decidió la colocación de una placa LCP 4.5 en $\mathrm{T}$ de 10 orificios para lograr un soporte adecuado de la lesión (figuras 2 y 3 ).

En recientes estudios se han descrito métodos adyuvantes como el denosumab, el cual debe agregarse al protocolo de tratamiento en pacientes que no pueden someterse a una resección total debido al tamaño del tumor y la localización anatómica. Sin embargo, no se recomienda el denosumab en pacientes pediátricos menores de 4 años debido a las altas tasas del crecimiento esquelético y la posibilidad de que denosumab afecte negativamente el crecimiento de los huesos largos y la dentición. Tratamiento con denosumab puede afectar el crecimiento óseo en niños con placas de crecimiento y puede inhibir la erupción de la dentición. ${ }^{17,18}$ 


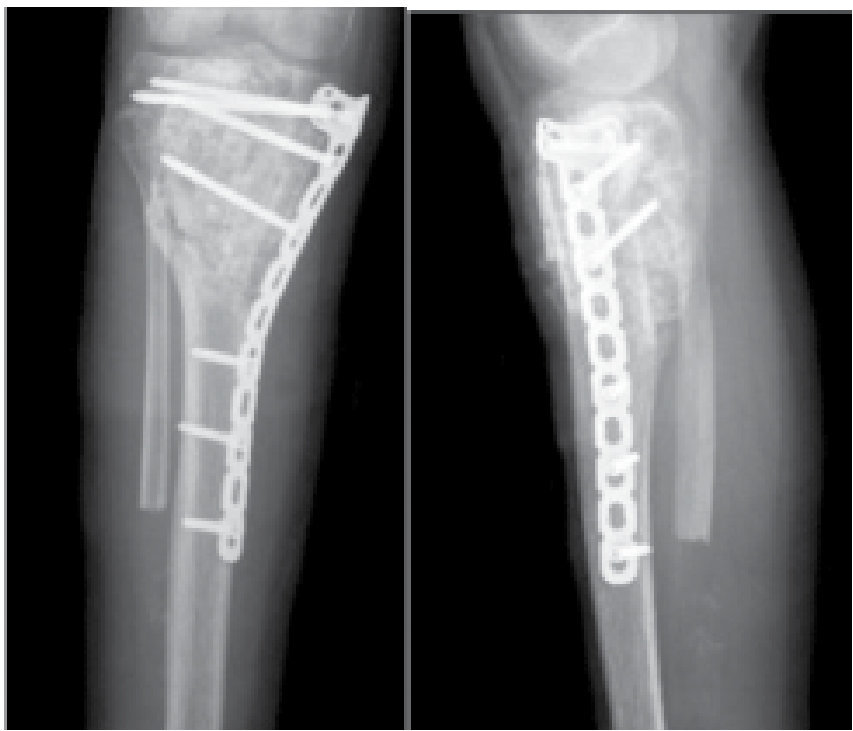

Figura 3. Radiografía postquirúrgica donde se observa integración del injerto

El caso que se presenta nos recuerda que el tumor de células gigantes no es exclusivo de la edad adulta. Aunque poco frecuente, la sospecha diagnóstica debe existir en los casos de dolor crónico, continuo y de creciente intensidad aun en pacientes pediátricos.

\section{Conclusiones}

Resulta importante considerar las formas infrecuentes en la presentación de estos tumores, para permitir un diagnóstico temprano y ofrecer mejores opciones de tratamiento que se traduzcan en una mejor calidad de vida. Las características del dolor, así como su cronicidad pueden orientar al diagnóstico diferencial de manera temprana, y prevenir la progresión de la enfermedad y la discapacidad. Existen pocos reportes de casos en pacientes pediátricos por lo que el tratamiento está basado en el ya descrito para pacientes adultos.

\section{Bibliografía}

1. Minhao Wu, Shiyi Yao, Yuanlong Xie, Feifei Yan, Zhouming Deng, Jun Lei, Lin Cai. A novel subchondral bone-grafting procedure for the treatment of giant-cell tumor around the knee $A$ retrospective study of 27 cases. Medicine. 2018; 97(45):1-10.

2. Ricardo K. Kalil. (2015). Giant Cell Tumor of Bone. En Tumors and Tumor-Like Lesions of Bone (351366). Buenos Aires, Argentina: Springer
3. Aguilar-Ezquerra Andrés, López-Subías Jorge, LilloAdán Marina, Peguero-Bona Antonio. Tratamiento de tumores de células gigantes. Revista Cubana de Ortopedia y Traumatología. 2015; 29(1):1-7.

4. Al-Ibraheemi A, Inwards CY, Zreik RT, Wenger $D E$, Jenkins SM, Carter JM, Fritchie KJ. Histologic Spectrum of Giant Cell Tumor (GCT) of Bone in Patients 18 Years of Age and Below. The American Journal of SurgicalPathology. 2016;40(12):17021712. doi: $10.1097 /$ pas. 0000000000000715 
5. Hongbo He, Hao Zeng, Wei Luo, Yupeng Liu, Can Zhang and Qing Liu. Surgical Treatment Options for Giant Cell Tumors of Bone Around the Knee Joint: Extended Curettage or Segmental Resection? Frontiers in Oncology. 2019; 9:1-10.

6. Omlor Georg W, Lange Jessica, Streit Marcus, Gantz Simone, Merle Christian, Germann Thomas, Mechtersheimer Gunhild, Fellenberg Jörg, Lehner Burkhard. Retrospective analysis of 51 intralesionally treated cases with progressed giant cell tumor of the bone: local adjuvant use of hydrogen peroxide reduces the risk for tumor recurrence. World Journal of Surgical Oncology. 2019;17(73):1-10. https://doi. org/10.1186/s12957-019-1613-9.

7. Luengo-Alonso Gonzalo, Mellado-Romero Maria, Shemesh Shai, Ramos-Pascua Luis, Pretell-Mazzin Juan. Denosumab treatment for giant-cell tumor of bone: a systematic review of the literature. Archives of Orthopaedic and Trauma Surgery. 2019; 1:1-11.

8. Valladares-Vijil Luis Daniel, Silva-Cárcamo Héctor, Armando-Dominguez Roger. Tumor de células gigantes de hueso: diagnóstico incidental en una paciente con artralgia de larga evolución. Arch de Medi. 2015; 11(4): 1-5.

9. Amanatullah DF, Clark TR, Lopez MJ, Borys D, Tamurian RM. Giant cell tumor of bone. Orthopedics. 2014;37(2):112-120. doi:10.3928/0147744720140124-08

10. De la Garza JM, Ceccopieri CA, Cruz H, Díaz LR, Martínez R. Tumor de células gigantes de hueso. Aspectos generales de 11 casos. Rev Med Hosp Gen Mex. 1999; 62(4): 240-244.
11. Echeverry PA, et al. Tumor de células gigantes óseo en niños y adolescentes: reporte de 11 casos. Rev Colomb Ortop Traumatol. 2017. http://dx.doi. org/10.1016/j.rccot.2017.06.006

12. Ajay Puri, Agarwal Manish. Treatment of giant cell tumor of bone: Current concepts. Indian J Orthop. 2007; 41(2):101-108.

13. Mavrogenis AF, Igoumenou VG, Megaloikonomos PD, Panagopoulos GN, Papagelopoulos PJ \& Souca$\cos \mathrm{PN}$. Giant cell tumor of bone revisited. SICOT J. 2017; 3:54.

14. Raskin KA, Schwab JH, Mankin HJ, Springfield DS, Hornicek FJJ. Giant cell tumor of bone. Am Acad Orthop Surg. 2013;21(2):118-26.

15. Bracamonte-Barahona R, Calderón-Sauri I, ChanJiménez J, Flores-Mendoza K, Alejos-Gómez R, Méndez-Domínguez N. Tumor de células gigantes de localización isquiopúbica en paciente pediátrico: reporte de caso clínico. Revista Mexicana de Ortopedia Pediátrica 2018; 20(2): 93-97.

16. Llamas LF, Tarango VM, Fuentes IL, Fajardo D. Tumor de células gigantes del hueso de localización infrecuente. Med Cutan Iber Lat Am. 2011; 39(5): 234-237.

17. Skubitz KM. Giant cell tumor of bone: current treatment options. Curr Treat Options Oncol. 2014;15(3):507-18.

18. Oktay, K., Guzel, E., Simsek, S., \& Guzel, A. (2018). Giant cell tumor of the eleventh thoracic vertebra in a pediatric patient: an interesting case report and comprehensive literature review. Child's Nervous System. 